\title{
Anti-idiotypic Antibodies against BP-IgG Prevent Type XVII Collagen Depletion
}

\author{
Mayumi Kamaguchi ${ }^{1,2}$, Hiroaki Iwata ${ }^{1 *}$, Yuiko Mori ${ }^{1}$, Ellen Toyonaga', Hideyuki Ujiie', \\ Yoshimasa Kitagawa $^{2}$ and Hiroshi Shimizu ${ }^{1}$
}

'Department of Dermatology, Hokkaido University Graduate School of Medicine, Sapporo, Japan, ${ }^{2}$ Department of Oral Diagnosis and Medicine, Graduate School of Dental Medicine, Hokkaido University, Sapporo, Japan

Bullous pemphigoid (BP) mainly targets type XVII collagen (COL17). Intravenous immunoglobulin (IVIg) is used to treat numerous autoimmune diseases, including BP. The major mechanism of action for IVIG is thought to be its immunomodulatory effect. However, little is known about the precise mechanisms of IVlg in BP. We investigate the cellular effects of IVIg, toward treatments for BP. Keratinocytes were treated with IgG from BP patients (BP-lgG) and with IVlg, and then the COL17 expression was detected by Western blotting. Cell adhesion and ex vivo dermal-epidermal separation were also investigated for the condition with BP-lgG and IVIg. BP-lgG targeting the non-collagenous 16A domain induces the depletion of COL17 in cultured keratinocytes

Edited by:

Falk Nimmerjahn, University of Erlangen-Nuremberg, Germany

Reviewed by: Bruce David Mazer, The Research Institute of the McGill University Health Center, Canada Jan Lunemann, University of Zurich, Switzerland

${ }^{*}$ Correspondence: Hiroaki Iwata hiroaki.iwata@med.hokudai.ac.jp

Specialty section: This article was submitted to Immunological Tolerance and Regulation,

a section of the journal

Frontiers in Immunology

Received: 29 August 2017 Accepted: 14 November 2017 Published: 27 November 2017

Citation:

Kamaguchi M, Iwata H, Mori Y, Toyonaga E, Ujiie H, Kitagawa $Y$ and

Shimizu H (2017) Anti-idiotypic Antibodies against BP-lgG Prevent

Type XVII Collagen Depletion.

Front. Immunol. 8:1669. doi: 10.3389/fimmu.2017.01669 (DJM-1 cells). The COL17 levels in DJM-1 cells were decreased by $50 \%$ after $4 \mathrm{~h}$ of BP-lgG stimulation as determined by Western blotting. By contrast, BP-lgG with IVIg was found to result in 70-90\% increases in COL17 and to restore adhesion to the plate. Interestingly, IVIg significantly inhibited the binding of BP-IgG to the COL17-enzymelinked immunosorbent assay plate, and this was due to anti-idiotypic antibodies against BP-IgG. When anti-idiotypic antibodies against BP-IgG in $0.02 \%$ of IVlg were depleted from IVIg, those antibodies did not exhibit inhibitory effects on COL17 depletion. When cryosections of human skin were incubated with BP-lgG in the presence of leukocytes, dermal-epidermal separation was observed. BP-lgG treatment with IVIg or anti-idiotypic antibodies did not induce such separation. These findings strongly suggest the presence of anti-idiotypic antibodies against anti-COL17 lgG in IVlg. This mechanism of IVlg could be a target for therapies against BP.

\begin{abstract}
Keywords: bullous pemphigoid, type XVII collagen, intravenous immunoglobulin, idiotypic antibody, depletion, autoantibody
\end{abstract}

\section{INTRODUCTION}

The first uses of intravenous immunoglobulin (IVIg) were in immunodeficient individuals and individuals with severe infections. IVIg is currently used to treat numerous autoimmune diseases, including rheumatoid arthritis, systemic lupus erythematosus, and autoimmune blistering diseases (AIBDs) (1). Controlled studies of IVIg as a treatment for pemphigus and pemphigoid patients found IVIg to be a safe, effective treatment $(2,3)$. Furthermore, several case reports have

Abbreviations: IVIg, intravenous immunoglobulin; AIBD, autoimmune blistering disease; EBA, epidermolysis bullosa acquisita; BP, bullous pemphigoid; COL17, type XVII collagen; NC16A, the non-collagenous 16A domain; RT, room temperature; BSA, bovine serum albumin; FcRn, neonatal Fc receptor; ELISA, enzyme-linked immunosorbent assay. 
described the use of IVIg to treat AIBDs such as pemphigoid and epidermolysis bullosa acquisita (EBA) (4-6). Although various modes of action for IVIg have been proposed in AIBDs, the mechanisms behind its effect are still not fully understood $(7,8)$. The major mechanism of action for IVIg in AIBDs is thought to be its immunomodulatory effect $(1,9-11)$. In addition, anti-idiotypic antibodies against pathogenic antibodies have been reported in autoimmune disorders $(1,12)$. Although there are many autoimmune disorders, anti-idiotypic antibodies against autoantibodies have been proved in only several autoimmune disorders (13-18).

Bullous pemphigoid (BP) is the most common AIBD (19). Two autoantigens, type XVII collagen (COL17, also called BP180) and BP230, which form a hemidesmosome, are targeted in $\mathrm{BP}$, and COL17 is particularly relevant to the pathogenesis (19). Antibody-induced tissue damage is a major pathology in autoantibody-mediated autoimmune diseases (20). The activation of complements and/or inflammatory cells, including neutrophils and eosinophils, is crucial to the development of clinical phenotypes in animal models (21-23). In addition, molecular or cellular mechanisms have been proposed. IgG from BP patients (BP-IgG) targeting the non-collagenous 16A (NC16A) domain of COL17 induces the depletion of COL17 in cultured keratinocytes (24). It is thought that the shortage of COL17 causes an insufficiency of hemidesmosomes during remodeling that eventually results in weak cell adhesion to the basement membrane (25).

Regarding treatments for BP patients, it has been reported recently that IVIg provides therapeutic benefits to BP patients (3). A randomized, double-blind, placebo-controlled clinical study concluded that IVIg has therapeutic benefits for patients with BP who are resistant to systemic steroid therapy. The inhibition of autoantibody production and inflammatory cascades are major strategies in BP treatment. Prednisolone is thought to have dual effects and is commonly used. In most BP treatments, the targets are immune cells, including neutrophils and antigenspecific B cells and/or T cells. However, little is known about the effects of IVIg in keratinocytes expressing the autoantigens. This study focused on the cellular effects of IVIg, for the treatment of BP.

\section{MATERIALS AND METHODS}

\section{BP Patients and Total IgG Purification}

The BP patients fulfilled both inclusion criteria: (i) clinical blistering or erosions on the skin and (ii) circulating autoantibodies against COL17 as detected by BP180-NC16A enzyme-linked immunosorbent assay (ELISA)/CLEIA (MBL, Nagoya, Japan). BP-IgG was purified from plasma obtained by apheresis in a severe BP patient. Total IgG was purified using a protein $G$ affinity column according to the manufacturer's instructions (GE Healthcare, Amersham, UK). In accordance with the Hokkaido University Hospital bylaws and standard operating procedures approved by the Hokkaido University Hospital Review Board, we obtained patient consent for experimental procedures to be performed at Hokkaido University Hospital. A full review and approval by an ethics committee were not required, according to local guidelines. The studies were conducted in accordance with the Helsinki guidelines.

\section{Anti-COL17 NC16A IgG Purification}

Anti-COL17 NC16A IgG was purified from total IgG using a protein $\mathrm{G}$ affinity column by means of the HiTrap HNS-activated HP column according to the manufacturer's instructions (GE Healthcare). Briefly, GST fusion COL17 NC16A was produced as previously described (26). The recombinant protein was coupled with the HiTrap NHS-activated HP column. The titer of anti-COL17-specific IgG was measured by indirect immunofluorescent staining. Indirect immunofluorescent staining using anti-COL17-specific IgG (concentration $0.1 \mathrm{mg} / \mathrm{ml}$ ) demonstrated titers greater than 1:32,000.

\section{Treatment Agents}

Two different IVIgs (Nihon Pharmaceutical Co., Ltd., Tokyo, Japan, and Baxter International Inc., Deerfield, IL, USA; diluted with PBS) were purchased and used for this study. The concentrations of each agent for the treatment are given in Section "Results" and the figure legends.

\section{Depletion of Anti-idiotypic Antibodies}

To deplete anti-idiotypic antibodies against anti-COL17 NC16A IgG, anti-COL17 NC16A IgG was coupled to a HiTrap NHSactivated HP column according to the manufacturer's instructions (GE Healthcare). IVIg was passed through the column to remove anti-idiotypic antibodies, and then flow-through fractions (the "IVIg-depleted" sample) and the elution fraction (the "idiotype" sample) were used for the depletion assay. To evaluate the depletion efficacy, 96-well microtiter plates (Maxisorp; Nunc, Roskilde, Denmark) were coated with purified anti-COL17 NC16A IgG (500 ng/well), normal human IgG and PBS. Nonspecific binding was reduced by blocking with protein-free blocking buffer (Thermo Fisher Scientific, Rockford, IL, USA) at room temperature (RT) for $1 \mathrm{~h}$. Plates were subsequently incubated with biotin-conjugated IVIg (1 $\mathrm{mg} / \mathrm{ml})$. IVIg was conjugated with biotin using a biotin labeling kit according to the manufacturer's instructions (Dojindo, Kumamoto, Japan). Finally, plates were incubated with HRP-conjugated streptavidin (Thermo Fisher Scientific) for IgG subclasses at RT for $0.5 \mathrm{~h}$.

\section{Cell Culture}

DJM-1 cells isolated from human skin squamous cell carcinoma (27) were cultured in DMEM. To investigate the depletion of COL17, cells were cultured to approximately $40 \%$ confluence (24). DJM-1 cells were pretreated with agents for $1 \mathrm{~h}$, and then BP-IgG (concentration $1 \mathrm{mg} / \mathrm{ml}$ ) was added to the culture media for 4 -h incubation. In some experiments, DJM-1 cells were treated with BP-IgG for $4 \mathrm{~h}$ followed by IVIg for $1 \mathrm{~h}$.

\section{Western Blotting}

For Western blot analysis of whole-cell lysates, cells were lysed in RIPA buffer (Thermo Fisher Scientific) containing a protease inhibitor cocktail (Sigma Aldrich), and the lysates were 
centrifuged. Each fraction was subjected to SDS-PAGE in $6 \%$ polyacrylamide gel. The gels were transferred onto nitrocellulose membranes. Blotting was performed using rabbit anti-COL17 (1:2,000 dilution) (26), rabbit anti- $\beta$-tubulin (Abcam, Tokyo, Japan, 1:20,000 dilution), and anti-integrin $\alpha 6$ (Santa Cruz, Dallas, TX, USA, 1:500 dilution) as the primary antibodies, followed by incubation with HRP-conjugated goat anti-rabbit or anti-mouse IgG (Life Technologies, 1:5,000 dilution). Signals were visualized with Clarity Western ECL Substrate (Bio-Rad Laboratories, Hercules, CA, USA).

\section{Enzyme-Linked Immunosorbent Assay}

BP180-NC16A ELISA was performed according to the manufacturer's instructions with minor modifications (MBL). Briefly, the ELISA plate was incubated with $100 \mu \mathrm{l}$ of $\operatorname{IVIg}(5 \mathrm{mg} / \mathrm{ml})$, bovine serum albumin (BSA, $5 \mathrm{mg} / \mathrm{ml}$ ), or PBS. Subsequently, the plate was incubated with $1 \mathrm{mg} / \mathrm{ml}$ BP-IgG with/without PBS washing. The ELISA index value was calculated according to the manufacturer's instructions. ELISA using sera from BP patients and healthy volunteers was performed without washing the plate after IVIg incubation.

\section{Cell Adhesion Test}

BP-IgG stimulation leads to reductions in COL17 amount and in cell adhesion to the culture plate (24). Cells were placed on a vortex mixer for 20 min after BP-IgG stimulation with/without IVIg pretreatment. The adhesion of DJM-1 cells to the bottom of the culture plate was assayed by determining the number of adherent cells after vibration. After PBS washing, cells that remained on the bottom of the culture plate were treated with $0.25 \%$ trypsin for $5 \mathrm{~min}$ at $37^{\circ} \mathrm{C}$. The released cells were counted using a blood cell counter under a microscope.

\section{Ex Vivo Dermal-Epidermal Separation Assay (Cryosection Assay)}

Ex vivo autoantibody-induced, neutrophil-dependent dermalepidermal separation was performed as described $(28,29)$. Briefly, $5-\mu \mathrm{m}$ cryosections from normal human skin were incubated with BP-IgG $(2 \mathrm{mg} / \mathrm{ml})$ in the presence or absence of $5 \mathrm{mg} / \mathrm{ml} \mathrm{IVIg}$ at $37^{\circ} \mathrm{C}$ for $1 \mathrm{~h}$. After washing with PBS, the slides were covered with a second slide that was taped at each end to form a chamber. Subsequently, $10^{7}$ cells $/ \mathrm{ml}$ of freshly isolated normal human leukocyte suspension was injected into the chamber and incubated at $37^{\circ} \mathrm{C}$ for $5 \mathrm{~h}$. Sections were subsequently stained with $\mathrm{H} \& \mathrm{E}$. We tested the experiments using two different blood donors.

\section{Statistical Analyses}

Statistical calculations were performed using SigmaPlot (Version 12.0, Systat Software, Chicago, IL, USA). To compare the parameters in the COL17-depletion assay and COL17-ELISA, one-way ANOVA test was used. A comparison of the COL17-ELISA using patient sera with/without IVIg was performed using the Wilcoxon signed-rank test. A $p$-value of $<0.05$ was considered statistically significant. The graphs present the median \pm SD.

\section{RESULTS}

\section{IVIg Prevents COL17 Depletion of Keratinocytes Induced by BP-IgG}

When DJM-1 cells are treated with BP-IgG, the amount of COL17 is decreased as determined by Western blotting (COL17-depletion assay) (24). In this study, we examined the effects of IVIg by means of a COL17-depletion assay. For a COL17-depletion assay, $40 \%$ confluent cells were incubated with BP-IgG (concentration: $1 \mathrm{mg} / \mathrm{ml}$ ) for $4 \mathrm{~h}$. The amount of COL17 relative to $\beta$-tubulin was determined by Western blotting. DJM-1 cells were treated with BP-IgG before (the pretreatment sample) or after (the posttreatment sample) the addition of serially diluted IVIg. BP-IgG without IVIg induced an approximately 50-60\% reduction of COL17 in DJM-1 cells. By contrast, BP-IgG pretreated with $5 \mathrm{mg} / \mathrm{ml} \mathrm{IVIg}$ restored the amount of COL17 by $70-90 \%(p<0.05$, Figure 1A). IVIg posttreatment after $4 \mathrm{~h}$ of BP-IgG stimulation did not influence COL17 depletion (Figure 1B). Given that IVIg has direct effects on keratinocytes, such as on caspase expression (30), we incubated BP-IgG with IVIg in advance and then added them to the culture medium together (simultaneous sample). The COL17 depletion was restored similar to that in Figure 1A (Figure 1C). The amount of integrin $\alpha 6$, which is a transmembrane protein that is a hemidesmosomal component, was unchanged (Figure 1D). The same concentration $(5 \mathrm{mg} / \mathrm{ml})$ of BSA and normal human IgG did not influence the amount of COL17 under any conditions (Figure 1D).

The highest concentration of IVIg $(5 \mathrm{mg} / \mathrm{ml})$ was designed based on the estimated serum concentration with standard daily IVIg treatment (0.4 g/kg/day) (3).

\section{IVlg Restores the Loss of Cell Adhesion That Is Induced by BP-IgG}

Furthermore, cell adhesion was found to be reduced by approximately 60\% under BP-IgG stimulation (Figure 2). Pretreatment with IVIg restored cell adhesion. Cells remaining in the culture plate were significantly increased with $5 \mathrm{mg} / \mathrm{ml}$ IVIg pretreatment $(p<0.05$, Figure 2). Pretreatment with $5 \mathrm{mg} / \mathrm{ml} \mathrm{IVIg}$ restored adhesion by $90 \%$ compared with normal IgG stimulation.

\section{IVlg Prevents BP-IgG Binding to COL17}

We subsequently investigated the mechanism of action of IVIg in this COL17-depletion assay. The titer of BP-IgG used for the COL17-depletion assay was measured with IVIg $(5 \mathrm{mg} / \mathrm{ml})$, BSA $(5 \mathrm{mg} / \mathrm{ml})$ or PBS by ELISA. ELISA plates were preincubated with either IVIg or BSA, and BP-IgG was subsequently added. To rule out the possibility of IVIg masking the antigen, the ELISA plate was washed with PBS after IVIg pretreatment, and then BP-IgG was added. Interestingly, $5 \mathrm{mg} / \mathrm{ml}$ IVIg (without washing) significantly inhibited the binding of BP-IgG to the ELISA plate ( $p<0.05$, Figure 3A). IVIg pretreatment (without washing) reduced the average titer by $30 \%$ compared with PBS pretreatment (Figure 3A, black bar). This inhibition was not observed using IVIg (with washing) or the same concentration of BSA. These results suggest that IVIg impairs BP-IgG's ability to bind to COL17, in which IVIg may function as an anti-idiotypic 


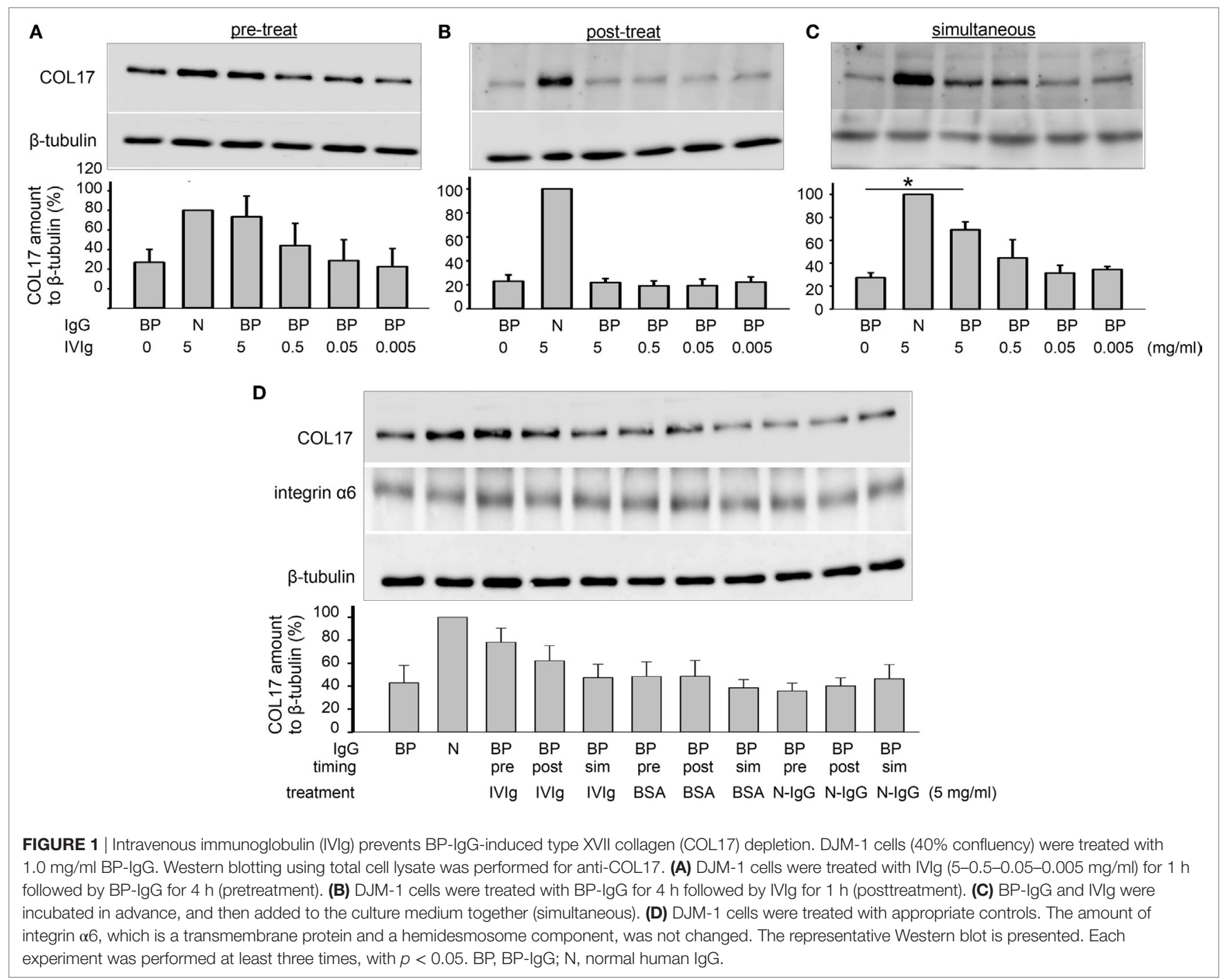

antibody. To confirm our results, samples from $10 \mathrm{BP}$ patients were evaluated in the same manner. The serum titers for all 10 patients were found to be reduced by approximately $40 \%$ in the presence of IVIg (without washing) ( $p<0.05$, Figure 3B).

\section{IVIg Contains Anti-idiotypic Antibodies against Anti-COL17 IgG}

Next, to confirm that anti-idiotypic antibodies were actually present in the IVIg, we performed experiments to identify them directly. Anti-idiotypic antibodies in the IVIg were depleted by anti-COL17 NC16A IgG (IVIg, IVIg depleted, and idiotype fractions, Figure 4A). IVIg contained approximately $0.02 \%$ of anti-idiotypic antibodies against COL17 IgG (Figure 4B). The depletion efficiency was more than $90 \%$ (Figure 4C). The titers of BP-IgG were measured in the presence of IVIg (IVIg $5 \mathrm{mg} / \mathrm{ml}$ and idiotype $2.6 \mu \mathrm{g} / \mathrm{ml})$ and normal IgG $(5 \mathrm{mg} / \mathrm{ml})$. The titers were found to be decreased in the setting of BP-IgG with IVIg and idiotype, but not BP-IgG with IVIg depleted (Figure 4D). Next, a COL17-depletion assay was performed using IVIg $(5 \mathrm{mg} / \mathrm{ml})$ and anti-idiotypic antibodies $(2.6 \mu \mathrm{g} / \mathrm{ml})$. IVIg depleted did not show blocking effects on COL17-depletion (Figure 4E). Furthermore, adhesion was also tested using IVIg and anti-idiotypic antibodies. IVIg depleted did not restore the adhesive strength compared with IVIg and idiotype (Figure 4F).

\section{IVlg Mitigates BP-IgG-Induced Dermal- Epidermal Separation on Cryosections}

According to our results, the therapeutic effects of IVIg potentially involve anti-idiotypic antibodies. We next examined the blocking effects of IVIg using an ex vivo assay, demonstrating the dermal-epidermal separation induced by BP-IgG in the presence of leukocytes $(28,29)$. In case of BP-IgG with PBS, dermal-epidermal separation was observed $5 \mathrm{~h}$ after incubation with normal human leukocytes (Figure 5, upper left). Next, we added IVIg, BSA and normal human IgG and incubated them with BP-IgG on the cryosections for $1 \mathrm{~h}$, followed by incubation with normal human leukocytes for $5 \mathrm{~h}$. IVIg depleted ( $5 \mathrm{mg} / \mathrm{ml}$, upper right) and normal human IgG (5 mg/ml, lower middle) did not block 


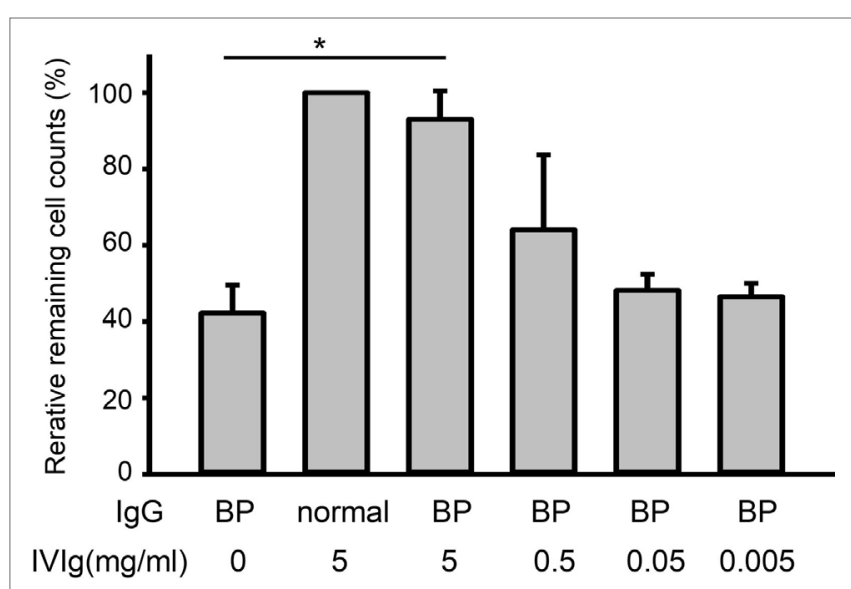

FIGURE 2 | Intravenous immunoglobulin (IVIg) restores the loss of cell adhesion induced by BP-lgG. DJM-1 cells were treated with $1.0 \mathrm{mg} / \mathrm{ml}$ BP-IgG. Culture plates were placed on a vortex for 20 min. After PBS washing, cells that remained on the bottom of the culture plate were counted using a blood cell counter under a microscope. The experiment was performed three times, with $p<0.05$.
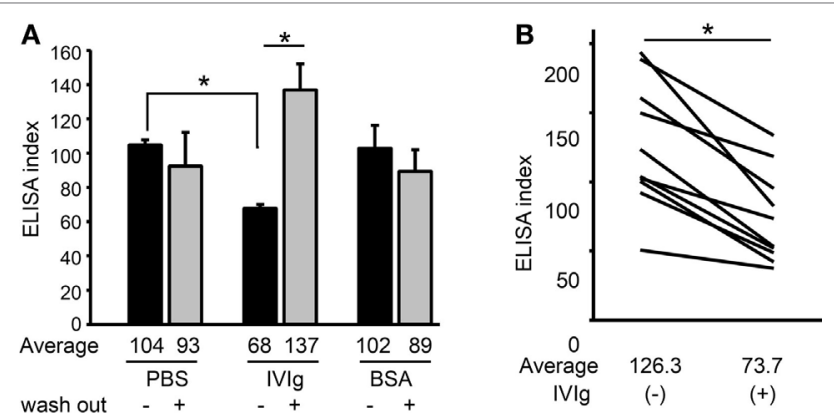

FIGURE 3 | Intravenous immunoglobulin (IVIg) prevents BP-lgG from binding to type XVII collagen (COL17). (A) BP-lgG titers were measured using a COL17-non-collagenous 16A enzyme-linked immunosorbent assay (ELISA) in the presence of IVIg and bovine serum albumin (BSA). The ELISA plates were washed with PBS after IVIg pretreatment to remove IVIg. Each experiment was performed four times. (B) The ELISA indexes of 10 BP patients' sera were measured with/without IVIg. Each experiment was performed three times, with $p<0.05$.

the dermal-epidermal separations. By contrast, IVIg $(5 \mathrm{mg} / \mathrm{ml}$, upper middle) and the idiotype $(2.6 \mu \mathrm{g} / \mathrm{ml}$, lower left $)$ protected the dermal-epidermal separation.

\section{The Results Were Reproduced Using a Different Company's Product}

There is great concern about differences arising from differences in IVIg lots or in companies. Therefore, we tested an IVIg from the different company. An IVIg product from this different company was found to prevent the COL17 depletion of keratinocytes induced by BP-IgG (Figure 6A). Furthermore, we found the same blocking effects of IVIg using an ex vivo assay (Figure 6B).

\section{DISCUSSION}

Intravenous immunoglobulin therapy is currently applied in autoimmune diseases, and various mechanisms of action for IVIg are involved. Previous clinical studies concluded that IVIg therapy for AIBD is a safe, effective strategy $(2,3,31-34)$. The modes of action of IVIg are divided into two major mechanisms (1). One mechanism involves the $\mathrm{F}(\mathrm{ab}) 2$ fragment, which is responsible for antigen recognition. The other mechanism involves the Fc fragment, which contributes to effector cell activation. Anti-idiotypic antibodies work via the $\mathrm{F}(\mathrm{ab}) 2$ fragment, which neutralize the pathogenic antibodies in several autoimmune disorders $(1,12)$. However, until now, there have been no reports on anti-idiotypic antibodies in BP. According to our COL17-depletion results, we expected IVIg to contain anti-idiotypic antibodies against BP-IgG and to prevent BP-IgG binding to autoantigen COL17. We clearly demonstrated the presence of very small amounts of anti-idiotypic antibodies against anti-COL17 $\operatorname{IgG}(0.02 \%)$ in IVIg. Even very small amounts of anti-idiotypic antibodies can prevent COL17 depletion. In addition, after the depletion of anti-idiotypic antibodies from IVIg, the ability of IVIg to block COL17 depletion was not observed. IVIg is purified from serum pooled from healthy volunteers; therefore, the IVIg used in this study may have contained anti-idiotypic antibodies to BP-IgG by chance. However, we ruled this out by reconfirming similar results using IVIg from a different company.

Although there are several lines of clinical evidence, the precise mechanisms of IVIg have yet to be fully elucidated in AIBD. $\mathrm{Li}$ et al. reported that IVIg therapy inhibited an experimental model of AIBD by accelerating the degradation of pathogenic IgG (9). This inhibitory effect of IVIg in experimental BP was completely dependent on the neonatal $\mathrm{Fc}$ receptor $(\mathrm{FcRn})$ via the $\mathrm{Fc}$ fragment. FcRn is associated with the half-life of IgG, and IgG recycled via FcRn increases that half-life (1). In an experimental model of EBA, IVIg exhibited therapeutic effects similar to those seen in systemic steroid therapy (10). In this EBA model, the disease was associated with neutrophil activation via the $\mathrm{Fc}_{\mathrm{c}}$ gamma receptor (FcgR) IV (35). Interestingly, IVIg treatment was found to reduce circulating autoantibodies and to modulate FcgRIV expression on neutrophils (10). FcgR modulation on neutrophils is also mediated by the Fc fragment of IVIg (1).

Systemic prednisolone is the most common and the most recommended therapy for BP $(19,36,37)$. Long-term prednisolone administration is associated with several risks, such as diabetes mellitus, infections, and osteoporosis. By contrast, IVIg is a safe, useful treatment for severe or high-risk cases, e.g., immunocompromised individuals or those with chronic viral infections, because it is less immunosuppressive. Although anti-idiotypic antibodies have been reported in several autoimmune disorders, a disease-specific therapy using anti-idiotypic antibodies has not been established. One major difficulty is that patients have polyclonal autoantibodies. Therefore, it is harder to neutralize polyclonal antibodies than it is in molecular-targeted therapies, such as anti-epidermal growth factor receptor therapy. BP may be a disease for which anti-idiotypic therapies have potential. The pathogenesis of BP-IgG has been clearly proved using animal models $(38,39)$. Autoantibodies from more than $80 \%$ BP patients 


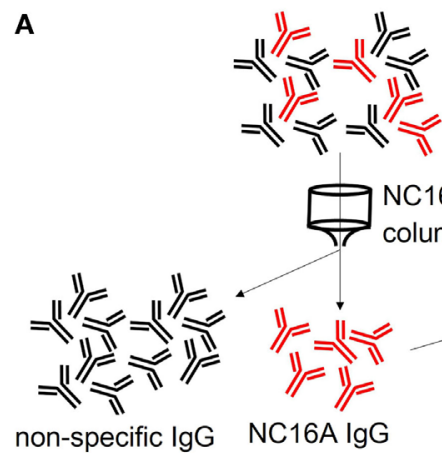

C

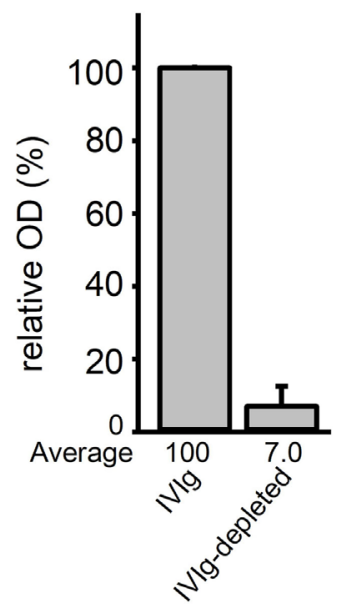

E

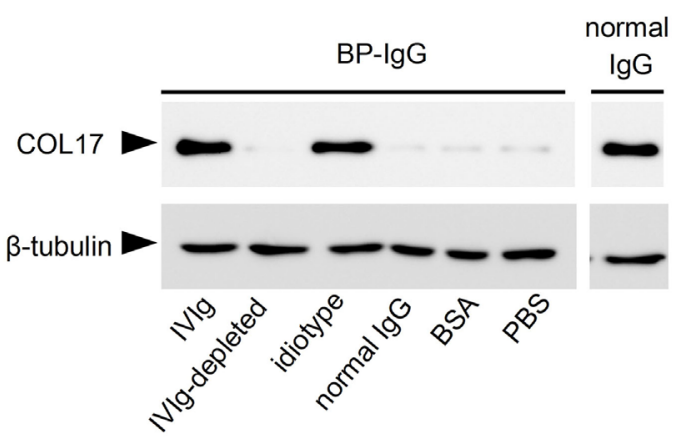

B

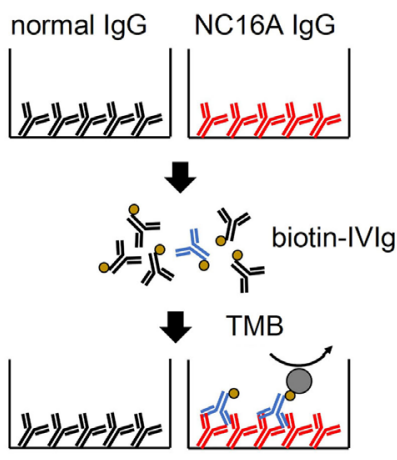

idiotype

D

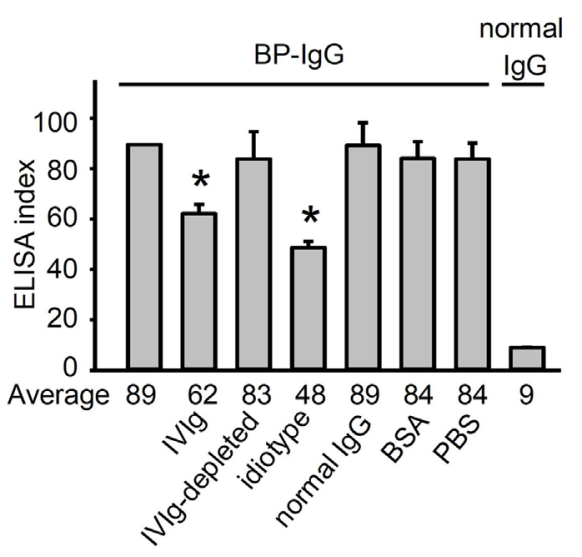

$\mathbf{F}$
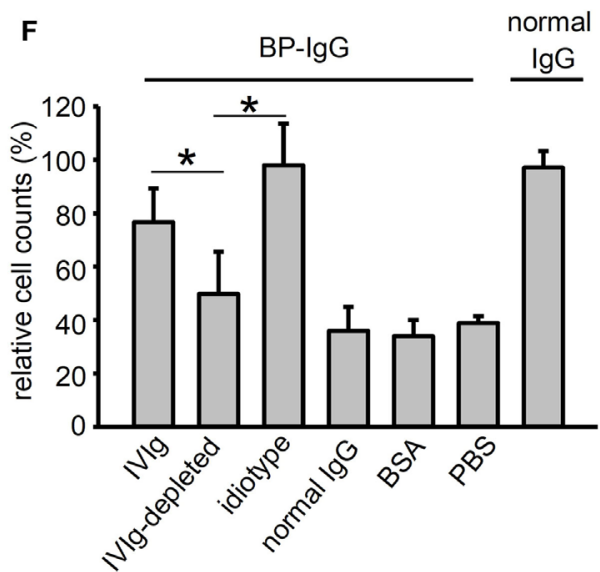

FIGURE 4 | Intravenous immunoglobulin (IVIg) contains anti-idiotypic antibodies against anti-type XVII collagen (COL17) IgG. (A) To deplete idiotypic antibodies, anti-COL17 non-collagenous 16A (NC16A) IgG was purified. Next, anti-COL17 NC16A IgG was coupled to a column. IVIg was passed through the column, and then the flow-through fraction (IVlg depleted) and the elution fraction (idiotype) were corrected. (B) To evaluate the depletion efficacy, 96-well microtiter plates were coated with anti-COL17 NC16A IgG and normal human IgG (500 ng/well). The plates were incubated with biotin-conjugated IVlg (1 mg/ml; idiotype sample: $0.1 \mathrm{mg} / \mathrm{ml})$. Finally, the plates were incubated with HRP-conjugated streptavidin. The depletion efficacy was calculated as follows: (IVlg-depleted OD to anti-COL17 NC16A IgG) - (IVlg OD to normal lgG) (IVlg OD to anti-COL17 NC16A) - (IVIg OD to normal lgG)

(5 mg/ml) against anti-COL17 NC16A lgG was determined. Using IVIg samples, the following were performed: (D) COL17 NC16A ELISA, (E) COL17-depletion assay, and $\mathbf{( F )}$ cell adhesion test. Bovine serum albumin (BSA) and normal human IgG at the same concentrations were used as controls. Data are based on duplicate samples, and each experiment was performed three times, with $p<0.05$. 

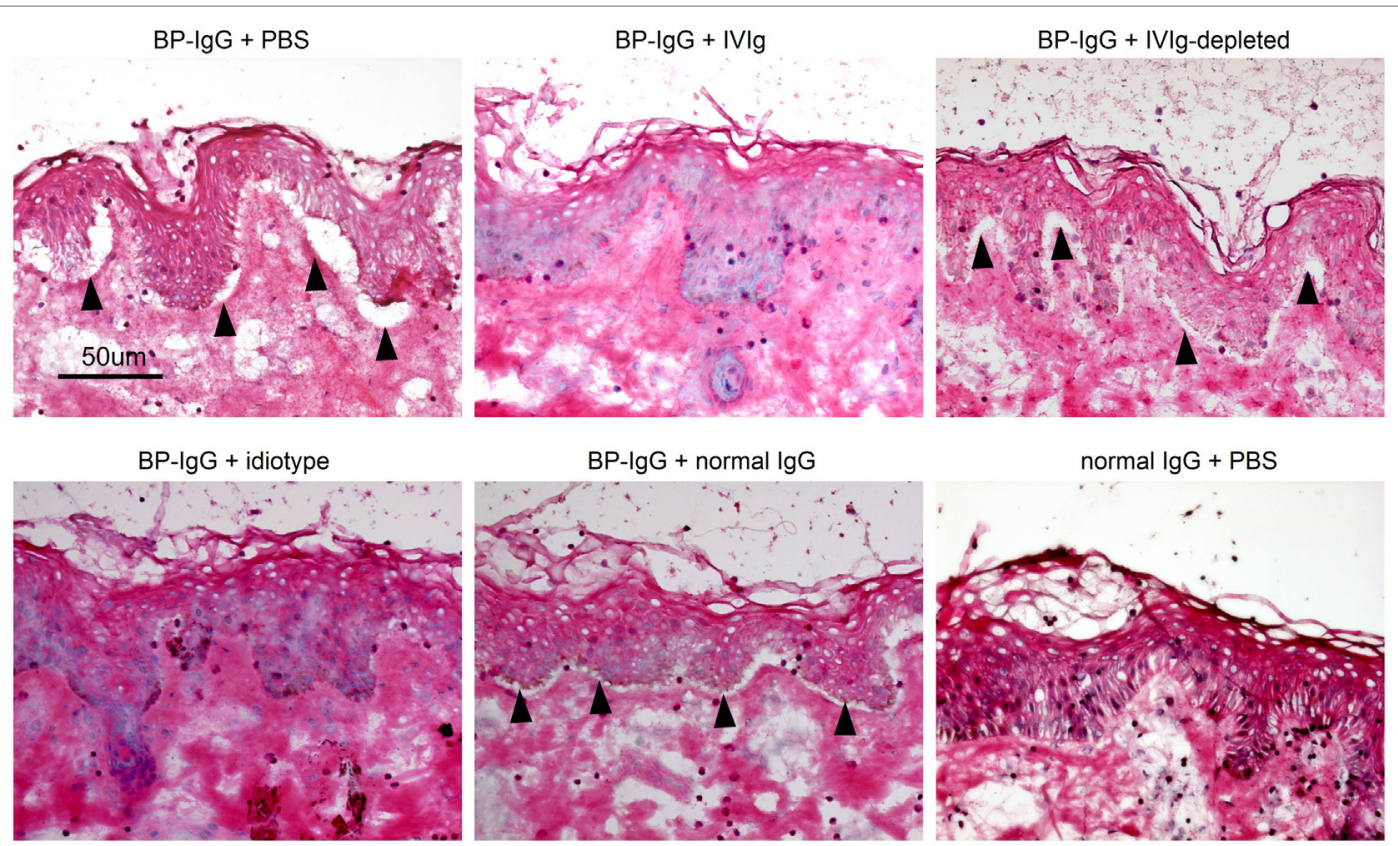

FIGURE 5 | Intravenous immunoglobulin (IVIg) prevents dermal-epidermal separation ex vivo. Cryosections of human skin were incubated with BP-lgG in the presence of IVlg $(5 \mathrm{mg} / \mathrm{ml}$, idiotype $2.6 \mathrm{\mu g} / \mathrm{ml})$ and normal human $\mathrm{lgG}(5 \mathrm{mg} / \mathrm{ml})$ for $1 \mathrm{~h}$. After washing with PBS, sections were incubated with freshly isolated human leukocytes $\left(1 \times 10^{7} \mathrm{cells} / \mathrm{ml}\right)$ for $5 \mathrm{~h}$. Arrows indicate dermal-epidermal separation. Each experiment was performed three times. Representative results for each setting are presented.

A

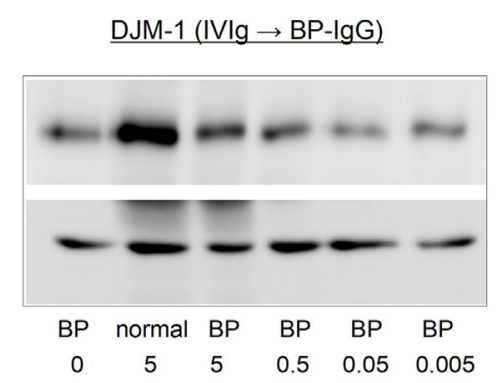

\section{B}
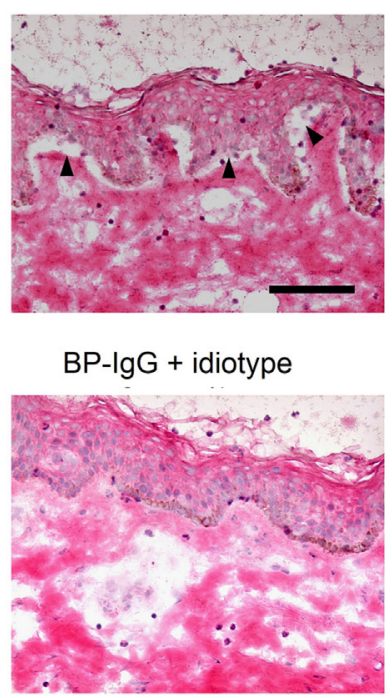

BP-IgG + IVIg

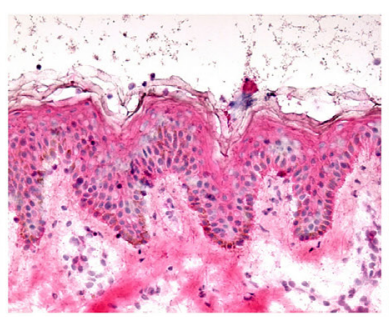

BP-lgG + normal lgG

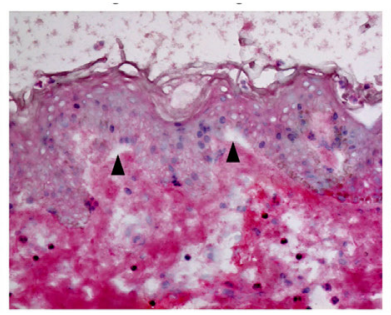

BP-IgG + IVIg-depleted

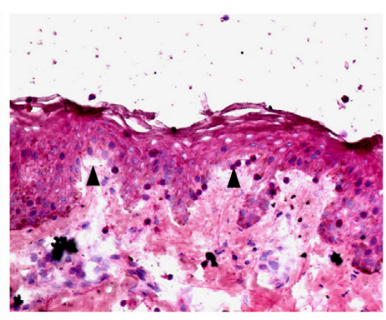

normal lgG + PBS

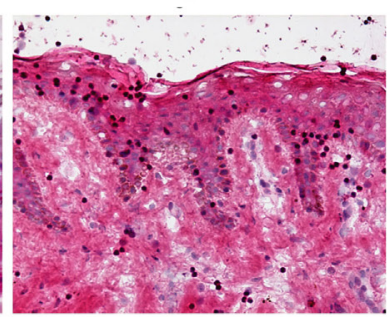

FIGURE 6 | A different company's intravenous immunoglobulin (IVIg) reproduces the results. Using IVIg from a different company, the type XVII collagen (COL17)depletion assay and ex vivo assay were performed. (A) COL17-depletion assay using IVIg from a different company (pretreatment). (B) Ex vivo assay using IVIg from a different company.

target to N-terminal 72 amino acids of the COL17-NC16A domain $(40,41)$. Furthermore, a precise epitope mapping study showed that 14 amino acids within the NC16A domain are recognized by $50-60 \%$ of BP sera (42). These indicate that BP-IgG may be less variable than other autoimmune disorders and may be neutralized effectively by anti-idiotypic antibodies. In conclusion, we demonstrated the effects of IVIg in preventing COL17 depletion induced by BP-IgG due to anti-idiotypic antibodies. This study is the first to demonstrate the presence of anti-idiotypic antibodies against anti-COL17 IgG in IVIg. Disease-specific 
therapies using anti-idiotypic antibodies may have potential as treatments for BP.

\section{ETHICS STATEMENT}

In accordance with the Hokkaido University Hospital bylaws and standard operating procedures approved by the Hokkaido University Hospital Review Board, we obtained patient consent for experimental procedures to be performed at Hokkaido University Hospital. The studies were conducted in accordance with the Helsinki guidelines.

\section{REFERENCES}

1. Schwab I, Nimmerjahn F. Intravenous immunoglobulin therapy: how does IgG modulate the immune system? Nat Rev Immunol (2013) 13(3):176-89. doi:10.1038/nri3401

2. Amagai M, Ikeda S, Shimizu H, Iizuka H, Hanada K, Aiba S, et al. A randomized double-blind trial of intravenous immunoglobulin for pemphigus. J Am Acad Dermatol (2009) 60(4):595-603. doi:10.1016/j.jaad.2008.09.052

3. Amagai M, Ikeda S, Hashimoto T, Mizuashi M, Fujisawa A, Ihn $\mathrm{H}$, et al. A randomized double-blind trial of intravenous immunoglobulin for bullous pemphigoid. J Dermatol Sci (2017) 85(2):77-84. doi:10.1016/j. jdermsci.2016.11.003

4. Segura S, Iranzo P, Martínez-de Pablo I, Mascaró JM Jr, Alsina M, Herrero J, et al. High-dose intravenous immunoglobulins for the treatment of autoimmune mucocutaneous blistering diseases: evaluation of its use in 19 cases. J Am Acad Dermatol (2007) 56(6):960-7. doi:10.1016/j.jaad.2006.06.029

5. Harman KE, Black MM. High-dose intravenous immune globulin for the treatment of autoimmune blistering diseases: an evaluation of its use in 14 cases. Br J Dermatol (1999) 140(5):865-74. doi:10.1046/j.1365-2133.1999.02817.x

6. Jolles S. A review of high-dose intravenous immunoglobulin (hdIVIg) in the treatment of the autoimmune blistering disorders. Clin Exp Dermatol (2001) 26(2):127-31. doi:10.1046/j.1365-2230.2001.00779.x

7. Ishii N, Hashimoto T, Zillikens D, Ludwig RJ. High-dose intravenous immunoglobulin (IVIG) therapy in autoimmune skin blistering diseases. Clin Rev Allergy Immunol (2010) 38(2-3):186-95. doi:10.1007/s12016-009-8153-y

8. Czernik A, Toosi S, Bystryn JC, Grando SA. Intravenous immunoglobulin in the treatment of autoimmune bullous dermatoses: an update. Autoimmunity (2012) 45(1):111-8. doi:10.3109/08916934.2011.606452

9. Li N, Zhao M, Hilario-Vargas J, Prisayanh P, Warren S, Diaz LA, et al. Complete FcRn dependence for intravenous Ig therapy in autoimmune skin blistering diseases. J Clin Invest (2005) 115(12):3440-50. doi:10.1172/JCI24394

10. Hirose M, Tiburzy B, Ishii N, Pipi E, Wende S, Rentz E, et al. Effects of intravenous immunoglobulins on mice with experimental epidermolysis bullosa acquisita. J Invest Dermatol (2015) 135(3):768-75. doi:10.1038/ jid.2014.453

11. Nagelkerke SQ, Kuijpers TW. Immunomodulation by IVIg and the role of Fc-gamma receptors: classic mechanisms of action after all? Front Immunol (2015) 5:674. doi:10.3389/fimmu.2014.00674

12. Kazatchkine MD, Kaveri SV. Immunomodulation of autoimmune and inflammatory diseases with intravenous immune globulin. $N$ Engl J Med (2001) 345(10):747-55. doi:10.1056/NEJMra993360

13. Tandon N, Jayne DR, McGregor AM, Weetman AP. Analysis of anti-idiotypic antibodies against anti-microsomal antibodies in patients with thyroid autoimmunity. J Autoimmun (1992) 5(5):557-70. doi:10.1016/0896-8411(92) 90153-H

14. Rossi F, Jayne DR, Lockwood CM, Kazatchkine MD. Anti-idiotypes against anti-neutrophil cytoplasmic antigen autoantibodies in normal human polyspecific IgG for therapeutic use and in the remission sera of patients with systemic vasculitis. Clin Exp Immunol (1991) 83(2):298-303. doi:10.1111/ j.1365-2249.1991.tb05631.x

15. Mimouni D, Blank M, Payne AS, Anhalt GJ, Avivi C, Barshack I, et al. Efficacy of intravenous immunoglobulin (IVIG) affinity-purified anti-

\section{AUTHOR CONTRIBUTIONS}

YM, MK, ET, and HI performed the experiments. HI, HU, YK, and HS designed the experiments. HI wrote the manuscript, and all the coauthors had final approval of the submission.

\section{ACKNOWLEDGMENTS}

The authors wish to sincerely thank Ms. Mika Tanabe for her technical assistance. This work was supported in part by a JSPS Grant-in-Aid for Young Scientists (B) (26860861 to HI).

desmoglein anti-idiotypic antibodies in the treatment of an experimental model of pemphigus vulgaris. Clin Exp Immunol (2010) 162(3):543-9. doi:10.1111/j.1365-2249.2010.04265.x

16. Evans MJ, Suenaga R, Abdou NI. Detection and purification of antiidiotypic antibody against anti-DNA in intravenous immune globulin. J Clin Immunol (1991) 11(5):291-5. doi:10.1007/BF00918187

17. Blank M, Anafi L, Zandman-Goddard G, Krause I, Goldman S, Shalev E, et al. The efficacy of specific IVIG anti-idiotypic antibodies in antiphospholipid syndrome (APS): trophoblast invasiveness and APS animal model. Int Immunol (2007) 19(7):857-65. doi:10.1093/intimm/dxm052

18. Shoenfeld Y, Rauova L, Gilburd B, Kvapil F, Goldberg I, Kopolovic J, et al. Efficacy of IVIG affinity-purified anti-double-stranded DNA anti-idiotypic antibodies in the treatment of an experimental murine model of systemic lupus erythematosus. Int Immunol (2002) 14(11):1303-11. doi:10.1093/ intimm/dxf099

19. Schmidt E, Zillikens D. Pemphigoid diseases. Lancet (2013) 381(9863): 320-32. doi:10.1016/S0140-6736(12)61140-4

20. Ludwig RJ, Vanhoorelbeke K, Leypoldt F, Kaya Z, Bieber K, McLachlan SM, et al. Mechanisms of autoantibody-induced pathology. Front Immunol (2017) 8(May):603. doi:10.3389/fimmu.2017.00603

21. Liu Z, Giudice GJ, Swartz SJ, Fairley JA, Till GO, Troy JL, et al. The role of complement in experimental bullous pemphigoid. JClin Invest (1995) 95(4):1539-44. doi:10.1172/JCI117826

22. Liu Z, Shapiro SD, Zhou X, Twining SS, Senior RM, Giudice GJ, et al. A critical role for neutrophil elastase in experimental bullous pemphigoid. J Clin Invest (2000) 105(1):113-23. doi:10.1172/JCI3693

23. Diny NL, Rose NR, Čiháková D. Eosinophils in autoimmune diseases. Front Immunol (2017) 8:484. doi:10.3389/fimmu.2017.00484

24. Iwata H, Kamio N, Aoyama Y, Yamamoto Y, Hirako Y, Owaribe K, et al. IgG from patients with bullous pemphigoid depletes cultured keratinocytes of the $180-\mathrm{kDa}$ bullous pemphigoid antigen (type XVII collagen) and weakens cell attachment. J Invest Dermatol (2009) 129(4):919-26. doi:10.1038/ jid.2008.305

25. Iwata H, Kitajima Y. Bullous pemphigoid: role of complement and mechanisms for blister formation within the lamina lucida. Exp Dermatol (2013) 22(6):381-5. doi:10.1111/exd.12146

26. Natsuga K, Nishie W, Shinkuma S, Ujiie H, Nishimura M, Sawamura D, et al. Antibodies to pathogenic epitopes on type XVII collagen cause skin fragility in a complement-dependent and -independent manner. J Immunol (2012) 188(11):5792-9. doi:10.4049/jimmunol.1003402

27. Kitajima $Y$, Inoue $S$, Yaoita $H$. Effects of pemphigus antibody on the regeneration of cell-cell contact in keratinocyte cultures grown in low to normal Ca++ concentration. J Invest Dermatol (1987) 89(2):167-71. doi:10.1111/1523-1747. ep12470554

28. Sitaru C, Schmidt E, Petermann S, Munteanu LS, Bröcker EB, Zillikens D. Autoantibodies to bullous pemphigoid antigen 180 induce dermal-epidermal separation in cryosections of human skin. J Invest Dermatol (2002) 118(4):664-71. doi:10.1046/j.1523-1747.2002.01720.x

29. Sitaru C. Experimental models of epidermolysis bullosa acquisita. Exp Dermatol (2007) 16(6):520-31. doi:10.1111/j.1600-0625.2007.00564.x

30. Arredondo J, Chernyavsky AI, Karaouni A, Grando SA. Novel mechanisms of target cell death and survival and of therapeutic action of IVIg in 
pemphigus. Am J Pathol (2005) 167(6):1531-44. doi:10.1016/S0002-9440(10) 61239-4

31. Sami N, Ali S, Bhol KC, Ahmed AR. Influence of intravenous immunoglobulin therapy on autoantibody titres to BP Ag1 and BP Ag2 in patients with bullous pemphigoid. J Eur Acad Dermatol Venereol (2003) 17(6):641-5. doi:10.1046/j.1468-3083.2003.00714.x

32. Arnold DF, Burton J, Shine B, Wojnarowska F, Misbah SA. An 'n-of-1' placebo-controlled crossover trial of intravenous immunoglobulin as adjuvant therapy in refractory pemphigus vulgaris. Br J Dermatol (2009) 160(5):1098-102. doi:10.1111/j.1365-2133.2009.09034.x

33. Ahmed AR, Gürcan HM. Treatment of epidermolysis bullosa acquisita with intravenous immunoglobulin in patients non-responsive to conventional therapy: clinical outcome and post-treatment long-term follow-up. J Eur Acad Dermatol Venereol (2012) 26(9):1074-83. doi:10.1111/j.1468-3083. 2011.04205.x

34. Gaitanis G, Alexis I, Pelidou SH, Gazi IF, Kyritsis AP, Elisaf MS, et al. Highdose intravenous immunoglobulin in the treatment of adult patients with bullous pemphigoid. Eur J Dermatol (2012) 22(3):363-9. doi:10.1684/ejd. 2012.1717

35. Kasperkiewicz M, Nimmerjahn F, Wende S, Hirose M, Iwata H, Jonkman MF, et al. Genetic identification and functional validation of FcyRIV as key molecule in autoantibody-induced tissue injury. J Pathol (2012) 228(1):8-19. doi:10.1002/path. 4023

36. Kirtschig G, Middleton P, Bennett C, Murrell DF, Wojnarowska F, Khumalo NP, et al. Interventions for bullous pemphigoid. In: Kirtschig G, editor. Cochrane Database of Systematic Reviews. Chichester, UK: John Wiley \& Sons, Ltd. (2010). CD002292 p.

37. Bernard P, Antonicelli F. Bullous pemphigoid: a review of its diagnosis, associations and treatment. Am J Clin Dermatol (2017) 18(4):513-28. doi:10.1007/ s40257-017-0264-2
38. Nishie W, Sawamura D, Goto M, Ito K, Shibaki A, McMillan JR, et al. Humanization of autoantigen. Nat Med (2007) 13(3):378-83. doi:10.1038/ nm1496

39. Liu Z, Sui W, Zhao M, Li Z, Li N, Thresher R, et al. Subepidermal blistering induced by human autoantibodies to BP180 requires innate immune players in a humanized bullous pemphigoid mouse model. JAutoimmun (2008) 31(4):331-8. doi:10.1016/j.jaut.2008.08.009

40. Schmidt E, Obe K, Bröcker EB, Zillikens D. Serum levels of autoantibodies to BP180 correlate with disease activity in patients with bullous pemphigoid. Arch Dermatol (2000) 136(2):174-8. doi:10.1001/archderm. 136.2.174

41. Kobayashi M, Amagai M, Kuroda-Kinoshita K, Hashimoto T, Shirakata Y, Hashimoto K, et al. BP180 ELISA using bacterial recombinant NC16a protein as a diagnostic and monitoring tool for bullous pemphigoid. J Dermatol Sci (2002) 30(3):224-32. doi:10.1016/S0923-1811(02)00109-3

42. Zillikens D, Rose PA, Balding SD, Liu Z, Olague-Marchan M, Diaz LA, et al. Tight clustering of extracellular BP180 epitopes recognized by bullous pemphigoid autoantibodies. J Invest Dermatol (1997) 109(4):573-9. doi:10.1111/1523-1747.ep12337492

Conflict of Interest Statement: The authors declare that the research was conducted in the absence of any commercial or financial relationships that could be construed as a potential conflict of interest.

Copyright @ 2017 Kamaguchi, Iwata, Mori, Toyonaga, Ujiie, Kitagawa and Shimizu. This is an open-access article distributed under the terms of the Creative Commons Attribution License (CC BY). The use, distribution or reproduction in other forums is permitted, provided the original author(s) or licensor are credited and that the original publication in this journal is cited, in accordance with accepted academic practice. No use, distribution or reproduction is permitted which does not comply with these terms. 